\title{
Extraction and Isolation of Withaferin A ( Steroidal Lactone) from Withania somnifera Leafs and It's TLC and HPLC Analysis
}

\author{
DHANANJAY DWIVEDI ${ }^{1}$, BHORIK YADAV $^{2}$ and NEHA SENGAR ${ }^{3}$ \\ 1'Department of Chemistry, P.M.B. Gujarati Science College, Indore, India. \\ ${ }^{2}$ Gurjar Phytochem, Indore, India. \\ ${ }^{3}$ Department of Chemistry, Umiya Girls College, Rau , Indore,India. \\ *Corresponding author E-mail- ddwivedi2009@gmail.com
}

http://dx.doi.org/10.13005/ojc/330360

(Received: April 06, 2017; Accepted: May 02, 2017)

\begin{abstract}
Withania Somnifera (Ashwagandha) is one of the most important ancient medicinal plant of Unani and Ayurvedic system of traditional medicine which is extensively used by tribal people world wide for many ailments. The leaves of the plant are bitter in taste and are applied for carbuncles, inflammation, swellings and conjunctivitis. In the present study phytochemical constituents present in withania somnifera leaf is studied by applying process of extraction and isolation and is analyzed by using TLC and HPLC method. The results show the presence of phytochemical ingredients like withanoside IV, withanoside V + VI, withaferin A, with astramonolide, withanolide A, withanone, withanolide B.
\end{abstract}

Keywords: Withanolides, Withania somnifera, HPLC, Withaferin A.

\section{INTRODUCTION}

Withania Somnifera, commonly known as Ashwagandha belong to family Solanaceae and is one of the most important ancient medicinal plant of Unani and Ayurvedic system of traditional medicine. ${ }^{1}$ The plant is mainly grows in drier parts of India and also cultivated for medicinal purpose. Withania Somnifera has wide range of bioactive compounds and extensively used by tribal people worldwide to cure many ailments. Traditionally , the plant is used to enhance energy, vigour, endurance, strength, health, vital fluids, muscle fat, blood, lymph, semen and cell production ${ }^{2}$. The plant is also useful in the treatment of burns, wounds, dermatological and gastrointestinal disorders, asthma, bronchitis, cancer and geriatric problems. It is called "Indian Ginseng" for its great rejuvenating properties ${ }^{3}$. The leaves of the plants are applied for carbuncles, inflammation and swelling and its juice is useful in conjunctivitis. ${ }^{4,5}$

Withanolids are steroidal compounds and mainly found in the leaves and roots of withania 
somnifera ${ }^{6,7}$. The leaves of Withania Somnifera are reported to contain a number of withanolides and alkaloids ${ }^{8}$. Withaferin $\mathrm{A}$ is the most important withanolide which is found in the leaves and roots of the plant.

\section{EXPERIMENTAL}

\section{Extraction and Isolation}

200 gram leaf powder were extracted in 2 Liter round bottom flask with reflux condenser at $70^{\circ} \mathrm{C}$ by $(80: 20)$ methanol : water three times, first extraction is $800 \mathrm{ml}$ for $3 \mathrm{hrs}$ second is $600 \mathrm{ml}$ for 3 hrs and third extraction is $600 \mathrm{ml} 3 \mathrm{hrs}$ collected all extracted material in solvent in 5 litre round bottom flask with distillation setting, distilled out solvent at $60^{\circ} \mathrm{C}$ under reduced pressure to a volume of $40 \mathrm{ml}$ and put it in a beaker kept overnight material were separated from liquid portion decant the liquid we get the material about 8 gram dry it under vacuum at $60^{\circ} \mathrm{C}$ get $6 \mathrm{gram}^{9}$.

6 gram material from above refluxes in $50 \mathrm{ml}$ pet ether 60-80 two times and decant the pet ether material is dry on silica for column chromatography 20 gram in air load on column with 25 gram silica gel for column chromatography eluted with Chloroform $150 \mathrm{ml}$ first fraction $\mathrm{CHCl}_{3}: \mathrm{CH}_{3} \mathrm{OH}(99: 1) 300 \mathrm{ml}$ second fraction, $\mathrm{CHCl}_{3}: \mathrm{CH}_{3} \mathrm{OH}$ (98.5: 1.5) third fraction and check on TLC show withaferin $A$ in the second and third fraction, Concentrated the second and third fraction under vacuum crystallized in methanol get $150 \mathrm{mg}$ of $85 \%$ purity.

\section{Analytical: TLC System Sample preparation}

i) $\quad 150 \mathrm{mg}$ standardized sample dissolve in 25 $\mathrm{ml}$ methanol and apply about 10 micro litre on TLC plate

ii) $100 \mathrm{mg}$ sample before eluted column

iii) 2 to $3 \mathrm{mg}$ sample dissolve in $10 \mathrm{ml}$ methanol and apply about 10 micro litre on TLC plate

Solvent system - Chloroform : Methanol (9.5:0.5) Detection - Spray Ethanol sulphuric acid reagen ${ }^{10}{ }^{10}$ black spot of withaferin $A$ appeared

\section{HPLC analysis}

Solution A: Dissolve $0.14 \mathrm{~g}$ of potassium dihydrogen phosphate in $900 \mathrm{~mL}$ of water, add
$0.5 \mathrm{~mL}$ of phosphoric acid, dilute with water to 1000 $\mathrm{mL}$, and mix.

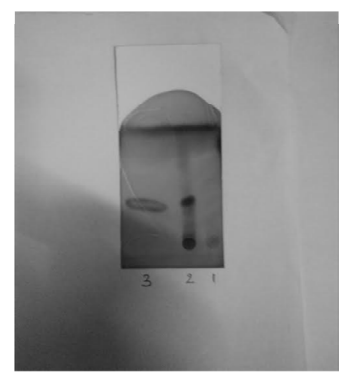

acetonitrile

Solution B: Filtered and degassed

\section{Standard solution 1}

Dissolve, using gentle heat, a quantity of standardized RS in methanol to obtain a solution having a known concentration of about $1.5 \mathrm{mg} / \mathrm{mL}$.

\section{Sample solution 2}

Dissolve, using gentle heat, a quantity of in methanol to obtain a solution having a known concentration of about $6 \mathrm{mg} / \mathrm{mL}$. ( before eluted on chromatographic column).

\section{Sample solution 3}

Transfer about $2 \mathrm{mg}$ of isolated crystallized Powdered of withaferin weighed, to a $25-\mathrm{mL}$ volumetric flask and make up with methanol to volume, and mix.

Before injection, all solution passes through a membrane filter having a $0.45-\mu \mathrm{m}$ or finer porosity, discarding the first few $\mathrm{mL}$ of the filtrate ${ }^{11}$.

Mobile phase: See the gradient table below.

\begin{tabular}{lcc}
\hline Time $(\boldsymbol{m i n})$ & Solution A(\%) & Solution B (\%) \\
\hline 0 & 95 & 5 \\
18 & 55 & 45 \\
25 & 20 & 80 \\
28 & 20 & 80 \\
30 & 95 & 5 \\
40 & 95 & 5 \\
\hline
\end{tabular}

Chromatographic system

Mode: LC

Detector: UV $227 \mathrm{~nm}$

Column: $4.6-\mathrm{mm} \times 25-\mathrm{cm}$, end-capped; packing 


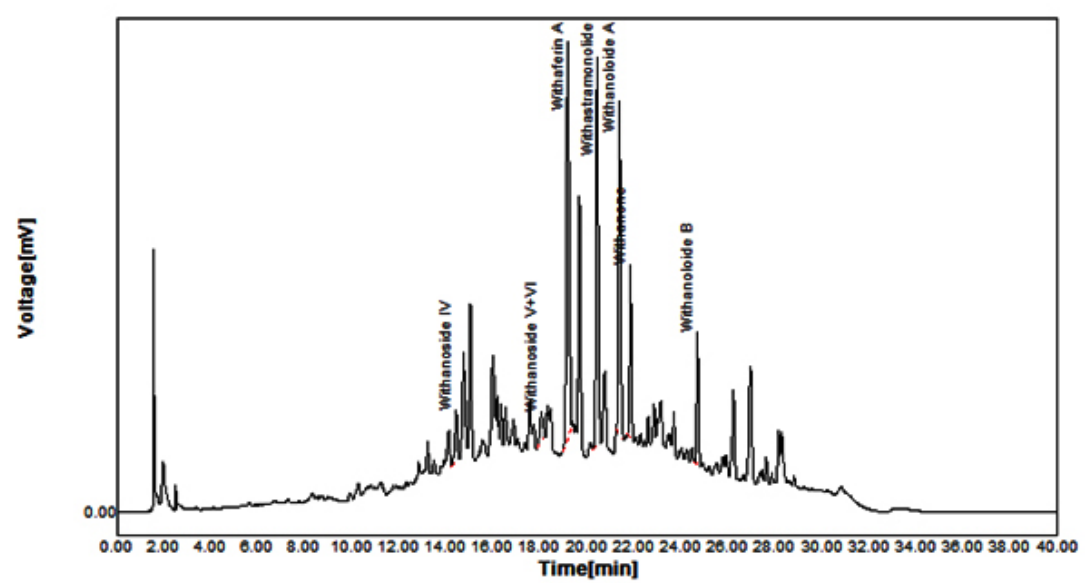

\begin{tabular}{ccccc}
\hline No. & Name & RT[min] & Area[mV*s] & Height[mV] \\
\hline 1 & Withanoside IV & 14.4167 & 77.8135 & 10.8373 \\
2 & Withanoside V+VI & 18.0500 & 56.4334 & 6.2853 \\
3 & Withaferin A & 19.1667 & 619.9073 & 81.2658 \\
4 & Withastramonolide & 20.4167 & 551.8586 & 79.9317 \\
5 & Withanoloide A & 21.3667 & 440.8266 & 68.3315 \\
6 & Withanone & 21.8333 & 184.5255 & 35.2502 \\
7 & Withanoloide B & 24.6833 & 148.1876 & 26.9866 \\
\hline
\end{tabular}

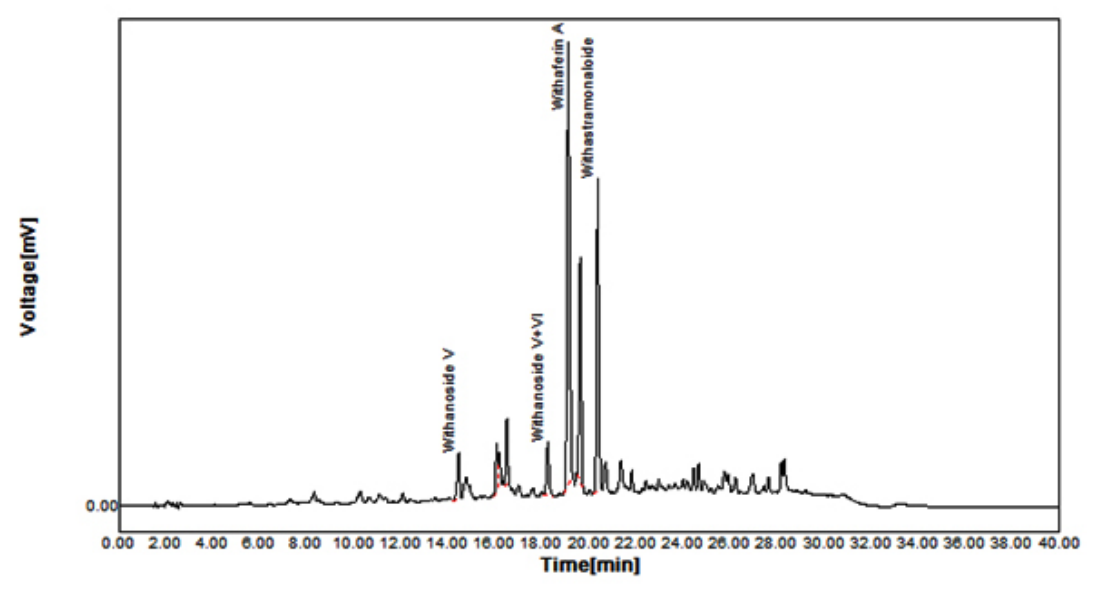

\begin{tabular}{lcccc}
\hline No. & Name & RT[min] & Area[mV*s] & Height[mV] \\
\hline 1 & Withanoside V & 14.4500 & 114.7165 & 16.0431 \\
2 & Withanoside V+VI & 18.2333 & 140.4946 & 18.8618 \\
3 & Withaferin A & 19.1000 & 1188.5211 & 158.2922 \\
4 & Withastramonaloide & 20.3500 & 773.3888 & 112.1440 \\
Sum & & & 2217.1211 & 305.3411 \\
\hline
\end{tabular}




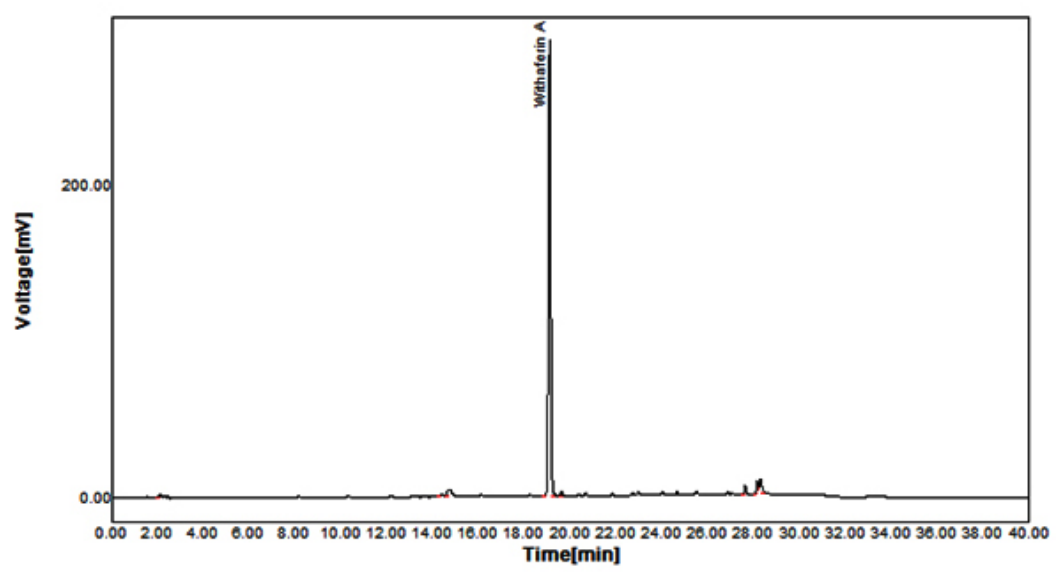

\section{No. Name RT[min] Area Height $\left[\mathrm{mV}^{*} \mathrm{~s}\right] \quad[\mathrm{mV}]$}

\section{$1 \quad$ Withaferin A $19.0833 \quad 1913.4049 \quad 292.0541$}

\section{L1}

Flow rate: $1.5 \mathrm{~mL} / \mathrm{min}$

Injection size: $20 \mu \mathrm{L}$

Sample Name:1- ASHWAGANDHA

Sample ID: NRPL STANDARDIZED

Date: 2016-10-17 PM 12:00:59

Channel:1. YL9120 UVD A

\section{RESULT}

Sample 2: Before eluted

Date: 2016-10-17 PM 12:41:59

Channel:1. YL9120 UVD A

\section{CHROMATOGRAM}

\section{RESULT}

Sample- 3

Isolated Withaferin A

\section{RESULT}

\section{DISCUSSION}

Sample 1,2,3 were analyzed as per standard conditions mentioned. Different components in sample of Withania somnifera had been estimated using HPLC, the active ingredients withanoside IV, withanoside $\mathrm{V}+\mathrm{VI}$, withaferin $\mathrm{A}$, withastramonolide, withanolide $A$, withanone and withanolide $B$ had been marked in the chromatogram obtained, sample 2 as given above is also run before eluted, their active ingredients and it's sum is mentioned in chromatogram, by analyzing sample-3 withaferin A is isolated.

\section{CONCLUSION}

Plant material obtained is authenticated first for its identification by taxonomist. It's extract is prepared, as mentioned earlier and phytochemical ingredients like withanoside IV, withanoside V + VI, withaferin $A$, withastramonolide, withanolide $A$, withanone, withanolide $B$ are studied using HPLC analysis, different peaks obtained confirm the presence of these active ingredients in sample, further it is attempted to isolate withaferin A, in it's pure form.

\section{REFERENCES}

1. Kumar, R.; Garipatti, V.; Hazare, K.; Mangal, A.K.; Sannd. R.International Journal
ofPharmacognosy and Phytochemical Research. 2013,5, 15-18. 
2. Kharel, P.; Manandhar, M.D.; Kalauni, S.K.;Awale, S.; Baral, J.Nepal Journal ofScience and Technology. 2011,12, 179186.

3. Saidulu, C.; Venkateshwar, C.; Rao, G.S. Biolife. 2014, 2, 306-312.

4. Shrivastav, A.K.; Das, P. International Journal of Innovative Research and Development. 2014,3, 22-33.

5. Mirjalili, M.H.; Moyano, E.; Bonfill, M.; Cusido, R.M.; Javier, P.Molecules. 2009, 14, 23732393.

6. Sumithradevi, S.; Pradeepa, D.; Senthil, K. Journal of Pharma and Bio Sciences. 2011, 2, 231-236.

7. Sangwan,R.S.; Chaurasiya, N.D.; Lal,
P.;Misra, L.PhysiologiaPlantarum. 2008, 133, 278-287.

8. Uddin, Q.; Samiulla, L.; Singh, V.K.; Jamil, S.S.Journal of Applied Pharmaceutical Science. 2012,2, 170-175.

9. Kokate, C.K.; Purohit, A.P.; Gokhale, S.B. Analytical Pharmacognosy, 45th Edi.,NiraliPrakashan Pune. 2010, 6-22.

10. Verma, A.; Ahirwar, A.K. International Journal of Research Studies in Biosciences. 2015, 3, 18-22.

11. Ingle, K.P.; Deshmukh, A.G.; Padole, D.A.; Dudhare, M.S.; Moharil, M.P.; Khelurkar, V.P.Journal of Pharmacognosy and Phytochemistry. 2017,6, 32-36. 